\title{
Optimized Design of Electric Propulsion System for Small Crafts using the Differential Evolution Algorithm
}

\author{
Dong Kun Lee',, Yong-Kuk Jeong', Jong Gye Shin ${ }^{3}$, and Dae-Kyun Oh' \\ 1 Department of Naval Architecture and Ocean Engineering, Mokpo National Maritime University, Haeyangdaehang-ro 91, Mokpo-si, Jeollanam-do, South Korea 530-729 \\ 2 Department of Naval Architecture and Ocean Engineering. Seoul National University, Gwanak-ro 1, Gwanak-gu, Seoul, South Korea 151-742 \\ 3 Department of Naval Architecture and Ocean Engineering and Research Institute of Marine Systems Engineering, \\ Seoul National University, Gwanak-ro 1, Gwanak-gu, Seoul, South Korea 151-742 \\ \# Corresponding Author / E-mail: dklee@mmu.ac.kr, TEL: +82-61-240-7322, FAX: +82-61-240-7301
}

KEYWORDS: Differential evolution, Electric propulsion system, Electric boat, Facility location problem, Operating performance evaluation, Small craft

\begin{abstract}
Given the stricter environmental regulations and rising oil prices, means of transportation based on eco-friendly fuel are drawing increased attention. Electric propulsion systems (EPSs) have been applied to various means of transportation, including cars, and many studies have examined ships equipped with EPSs. Generally, because of the low energy density of the battery, EPS-equipped vehicles experience the disadvantages of limited operating time and distance compared to fossil fuel-based vehicles. In this study, we developed an algorithm that determines the optimal electric motor and battery specifications for the basic requirements of a small craft equipped with an EPS. Moreover, to control the stability of the craft, we developed an algorithm that optimally arranges EPS components, wherein the center of gravity is used as an object function. The differential evolution algorithm was used for optimization, and the effectiveness was verified by applying this algorithm to the actual design of a small craft. The proposed algorithm represents the research results for determining the basic EPS specifications for a small craft and deriving an optimal arrangement for these specifications. This algorithm is expected to be effectively applied to design a new electric propulsion ship or to convert an existing ship to an electric propulsion ship.
\end{abstract}

\section{Introduction}

The process of designing a propulsion system for general vehicles, including ships, is essential. Since the invention of the diesel engine, most vehicles have used the energy generated by burning fossil fuels as their primary means of power. However, studies and application cases related to eco-friendly propulsion systems are increasing because of the consistently rising oil prices and increasing interest in environmental protection. The electric propulsion system (EPS), which rotates the motor using electrical energy, is a representative environmentally friendly propulsion system. ${ }^{1}$

Products that apply various EPSs, such as electric and hybrid cars, are widely used. Ships equipped with EPSs have been produced and researched since the 1980s. The EPS, in general, has the advantage of using space effectively because it occupies a smaller volume or weight than a conventional propulsion system. ${ }^{2}$ In addition, the EPS has the advantage of a flexible component arrangement because the power is not transmitted mechanically, but through electrical signals between the components of the EPS. The resistance applied to an operating ship is also affected by the ship's equilibrium position. In the case of electric propulsion ships, the EPS is able to control the balance of the ship by using electrically connected batteries. Moreover, the AC motor used in EPSs can rapidly change the rotating direction and speed by changing the frequency; thus, the electric propulsion ship has excellent maneuverability and is able to quickly attain high output or change direction. For these reasons, studies are currently applying EPSs to tugboats, icebreakers, or high-speed ships. ${ }^{3}$ However, vehicles equipped with EPSs experience the disadvantage of limitation in driving range compared with conventional vehicles.

For this reason, this study proposed an algorithm to design an EPS for a small craft that overcomes these disadvantages. Thus, a process was defined to determine the specifications of EPS components by finding a combination of the capacities of the motor and battery to compose an EPS that satisfies the user's requirements. In addition, considering that the ship's equilibrium position greatly affects resistance performance, this study proposed an optimal arrangement algorithm that can derive an 
arrangement to satisfy a specific center of gravity.

To discuss these subjects, this paper is structured as follows. Chapter 2 introduces the prior studies related to this study, and Chapter 3 proposes the operating performance evaluation (OPE) process, which determines the specifications of EPS components. Chapter 4 presents an algorithm that determines the optimal arrangement of EPS components, derived from the OPE process in Chapter 3. Finally, in Chapter 5, the algorithm proposed in this study is applied in the process of converting the conventional propulsion system into an EPS, to verify the effectiveness of the algorithm. The details of each step are described in the body of this paper.

\section{Literature Review}

\subsection{Electric Propulsion System for General Vehicles}

EPSs have been developed in design and application technologies for various means of transportation, primarily centered around cars. However, in the case of electric cars, the driving distance is generally one-third that of a gasoline car, and most countries still lack the infrastructure for recharging batteries. These are major factors preventing the charging-type electric car market from vitalizing. ${ }^{4}$ These factors result from the energy density of a battery: it stores electric energy, but its density is remarkably low compared to that of gasoline. ${ }^{5}$ As battery-related technology advances in the future, this phenomenon can be resolved. Nevertheless, vehicles using EPSs currently require a propulsion system design that takes into account the operating distance or energy consumption.

Route type, driver's driving style, and ambient temperature are major factors that affect the driving range of electric cars. ${ }^{2}$ Actually, Tesla Co., which sells advanced electric cars, provides a service to identify the driving range according to the consumer's characteristics based on these factors. In related studies, one research case derived a computing expression for calculating the energy consumption of an electric car based on the energy quantity loaded in the battery of the car. ${ }^{6}$ Recently, studies have applied EPSs not only to cars but to heavy equipment such as excavators and tractors. ${ }^{7,8}$

\subsection{Electric Propulsion System for Small Craft}

The component composition of the EPS varies according to its intended types or applications. In research on the scheme of an EPS for ships, components were defined as prime mover, synchronous generator, power transformer, motor drive, motor propeller, and other load demands, as shown in Fig. 1. This study composes an EPS scheme for a ship; the components of EPSs vary depending on the type or purpose of the target to which the system is applied. ${ }^{9}$

The EPS components defined in the above research include a generator and a prime mover for driving the generator; the prime mover adopts a diesel engine, a gas turbine, or a nuclear driving device. This is an indirect EPS. Energy loss occurs in the process of converting the energy generated at the prime mover to electric energy, but the overall efficiency increases compared to conventional propulsion systems because the energy losses occurring at the gearshift or axis transmission are reduced. Such indirect EPSs are applied to warships or large passenger ships that require large amounts of electricity for efficient use of electric power. ${ }^{10}$
Contrarily, a direct EPS, which does not equip a generator and drives the propulsion system by using the electric power stored in the battery, consists of a battery, a power converter, a motor, and a propeller, as shown in Fig. 2. ${ }^{11}$ The fuel quantity injected into the generator in the indirect EPS has a limit, but has more space to calculate possible operating distance than the direct EPS; as mentioned above, the energy density of gasoline is greater than that of a battery. However, the direct EPS does not have a separate energy source to supply power to the propulsion system when the battery is discharged completely. Thus, it is necessary for the user of a ship equipped with a direct EPS, as with a full electric vehicle, to recognize the possible operating distance. The subject of this study is a direct propulsion system that does not equip a generator; the final objective is to derive the specifications of motor and battery among EPS components. In addition to the aforementioned case, many studies are being conducted on various electric propulsion ships, such as fuel cell boats and hybrid electric propulsion ships. ${ }^{12-14}$

\subsection{Arrangement Problem}

In general, an arrangement problem is divided into a bitmap-based arrangement problem, which arranges the defined components on a grid, and a curve-based arrangement problem, which arranges the defined components in a continuous space. ${ }^{15}$ In a bitmap-based arrangement problem, the shape is expressed differently depending on the size of the unit grid; however, its advantage is that the arrangement result can be expressed rapidly. The advantage of a curve-based arrangement problem is that it can directly reflect the actual shape, but its disadvantage is that defining the problem is difficult. The complexity of the problem is greatly increased.

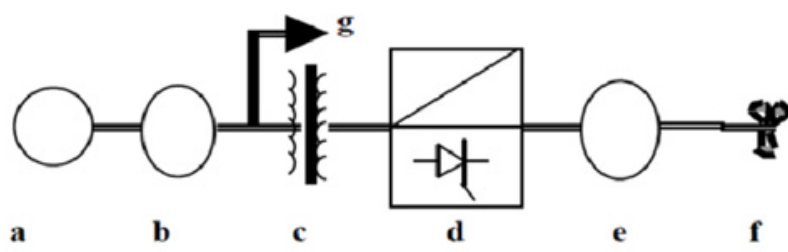

a. Prime mover (diesel engine or natural gas/COGEN)

b. Synchronous generator

c. Power transformer

d. Motor drive (frequency converter)

e. Motor (synchronous/inductive)

f. Propeller

g. Other load demands (pumps, winches, and lighting)

Fig. 1 Basic components of indirect EPS $^{9}$

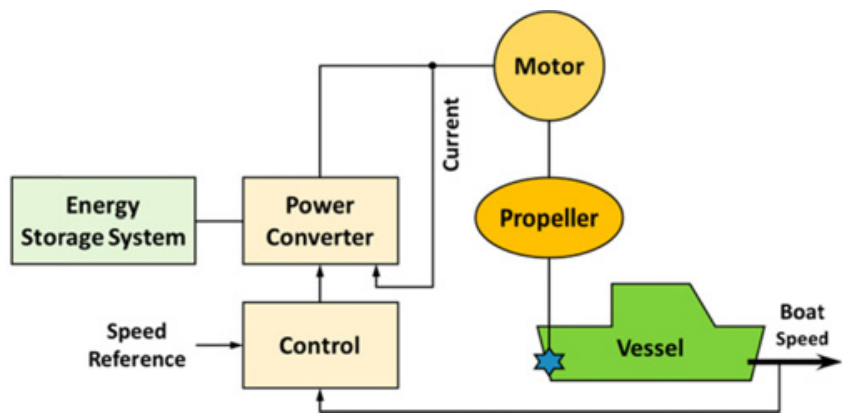

Fig. 2 Basic components of direct EPS ${ }^{11}$ 
The space filling curve (SFC) is a curve that fills the square spaces in a grid shape without missing any space by using the repeating rule. This curve passes all grids without missing any space, so it is possible to allocate serial numbers to grids in the curve creation sequence. If a serial number is allocated to a component that fits a limited area, then by following the arrangement order determined in advance, it can quickly derive the two-dimensional arrangement. However, the disadvantage is that the shape of this arrangement result is directly affected by the shape of the SFC. This problem may be resolved by adding a constraint condition to the shapes of the subjects to be arranged. ${ }^{16}$

The differential evolution (DE) algorithm is a comparatively recently proposed combinatorial optimization algorithm that uses evolutionary strategy. ${ }^{17}$ This algorithm seeks a global optimal solution by using the vectors defined in a solution space and the difference between these vectors. It can be applied not only to combinatorial optimization but also to continuous optimization because it uses vectors expressed with real numbers. In general, the DE algorithm is composed of four stages: initialization stage, in which it generates the initial solution; mutation stage, using a variety of searching directions; crossover stage, in which it combines vectors to prevent the solution from converging to a local optimal solution; and selection stage, in which it chooses a vector that has an excellent object function value. We conducted optimization in various fields using the DE algorithm because, as mentioned above, it can be applied not only to combinatorial optimization problems but to continuous optimization problems. ${ }^{18-20}$

\section{Evaluation Process of Operating Performance}

\subsection{Introduction}

The OPE process for small electric crafts evaluates the possible operating distance and time of an electric propulsion ship, which were defined when the ship was built according to the specifications in the designing stage of electrically propelled small crafts; it is based on the OPE process for the EPS proposed in previous research. In the previous study, the OPE process for the EPS was divided into five stages: requirement analysis stage, input data definition stage, EPS design stage, EPS evaluation stage, and result analysis stage. ${ }^{21}$ Operating time, operating speed, model test information, and EPS component plan were used as input data. The specifications of the battery and motor were determined based on these factors. After composing the EPS, the operating time was calculated by dividing the whole energy of the electric propulsion ship by energy consumption per unit time. The above research considered the energy produced at the generator in addition to that produced at the battery, because it included generators in the proposed process for the EPS.

This study elaborated on the contents of preceding studies and proposed an evaluation process for the operating performance of an EPS that does not include generators. First, the designer of the electric propulsion ship defines the requirements and derives the specifications of the battery, motor, and operating speed based on the requirements. When selecting a motor, the designer calculates the maximum output of the motor based on the relationship between the speed and resistance of the ship. The designer determines the battery specifications and operating speed in a similar way as in the method proposed in previous research. The specifications of the motor and the battery determined through these processes are used as input data for deriving the optimal arrangement of EPS components. The overall flow of the OPE process is shown in Fig. 3.

\subsection{Definition of Requirements}

To design an EPS, the requirements must be defined according to the purpose and usage of the electric propulsion ship. For example, in the case of a passenger boat operating in inland water, the maximum

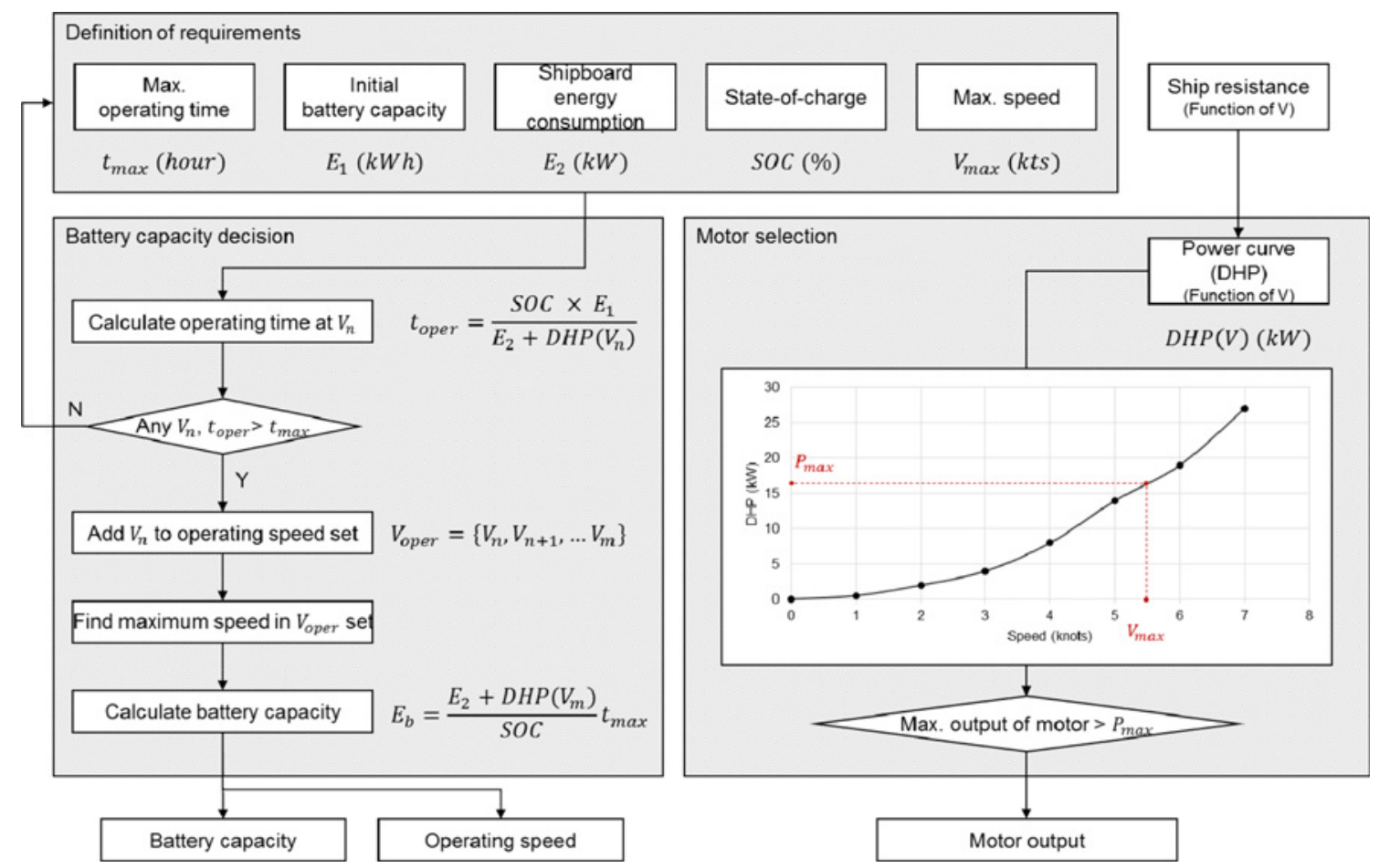

Fig. 3 Evaluation process for operating performance 
speed does not have to be fast and the operating time should be suitable for inland water sightseeing. On the contrary, in the case of a water leisure craft, the requirements must be determined to increase the maximum speed rather than the operating time. In this way, the maximum speed $\left(V_{\max }\right)$ and the maximum operating time $\left(t_{\max }\right)$ are defined in the requirement definition stage. The maximum operating time means minimum required operating time at a rated operating speed of the design craft. The defined requirements are used as the termination conditions of the OPE process for the EPS. In addition, the subject ship's resistance performance, regarding its speed and approximate capacity of the battery $\left(E_{1}\right)$, are required for designing an EPS. The information about resistance performance is required to determine the maximum output of the motor equipped on the ship and its energy consumption. In this study, if a model test was conducted so that the performance information of the target ship's resistance was available, then it is reflected in the design. If a model test was not conducted, the resistance performance was derived by using various estimation formulas that estimate the ship's resistance. The amount of energy consumed by the ship's motor during operation is calculated from its resistance performance information, and the other energy consumed in the ship or by its fittings is assumed as a constant $\left(E_{2}\right)$. Each variable is detailed in Fig. 3.

\subsection{Selection of Motor}

The required output of the propulsion system is determined by the value derived by multiplying resistance by the speed of the ship and considering the energy loss at a shaft or gearshift. It is characteristic of diesel engines that the output is proportional to the rotational speed. Thus, a high output cannot be reached when the rotational speed is low. A design point that meets the requirements and maximizes the efficiency of the propeller connected to the diesel engine is selected as the design point of the diesel engine. ${ }^{22}$ Currently, the design point can be determined only at a high rotational speed, owing to the characteristic of the diesel engine to produce a high output. Therefore, the disadvantage to a single diesel engine is that the range of a designer's decision is limited.

The output characteristic according to the rotation speed of an electric motor is unlike that of a diesel engine. The power output is proportional to the rotational speed in the diesel engine, but the power output remains constant if the rotational speed is beyond a certain level, as in the case of electric motors. The rotational speed, which the constant output maintains, is the base speed; the torque is maintained constantly by the power-torque relationship until it reaches the base speed. ${ }^{23}$ This characteristic of motors makes it possible to select design points in a wider range than with diesel engines. Therefore, electric motors have an advantage over diesel engines: various alternatives to the same design point can be considered.

The maximum output and rotational speed must be determined to select a motor. The output of a motor can produce the previously defined maximum speed as a requirement, and the high-speed motor is advantageous to electric propulsion ships in which space is limited; electrically, the faster the rotational speed, the smaller the motor. However, in general, the rotational speed of a ship's propeller is lower than that of a car, which frequently uses the motor. Therefore, after equipping it with a high-speed motor, a step-down gear is required to maintain the same propeller performance as before.

Through these processes, the selection of a suitable motor from the database of motors for electrically propelled ships was defined in advance, based on the derived output of the motor. In this study, a database of motors for electric propulsion ships was implemented, as listed in Table 1 , by analyzing the catalog of WEG Co., ${ }^{24}$ which describes various types of motors. It includes not only the geometric shapes of motors but also weight information, which is used for calculating the center of gravity when it is installed in the future.

\subsection{Battery Capacity Decision}

In the battery capacity determination stage, the possible available time is calculated by dividing the provided initial battery capacity $\left(E_{1}\right)$ by the sum of the electric power used for propelling a ship (DHP) and the electric power used in a ship $\left(E_{2}\right)$. The upper limit state-of-charge (SoC) of a battery is assumed to use $75 \%-85 \%$ of its total capacity because the ship cannot be used when the battery is completely discharged. The detailed computing process is shown in formula (1).

$$
t_{\text {oper }}=\frac{S O C \times E_{1}}{E_{2}+\operatorname{DHP}\left(V_{n}\right)}
$$

In formula (1), $t_{\text {oper }}$ is the possible operating time when the ship operates at a specific speed; $V_{n}$ is the speed a designer has chosen from the ship's possible operating speeds. The possible operating time should be greater than the maximum operating time required in the design process. If an operating time that satisfies the maximum operating time is not derived, the maximum operating time should be satisfied by increasing the battery capacity.

If many speeds are derived that satisfy the condition of maximum operating time, then the largest speed among these is determined to be the operating speed of the electric propulsion ship. The battery capacity is determined for a ship to operate at this speed for the maximum time entered by the user. In general, batteries mounted on the means of transportation are made to order in large quantities or are composed of unit cells. Therefore, the battery pack according to the total energy requirements should be composed at the battery composing stage by choosing a suitable unit battery cell. At this time, it is safe to compose a low-voltage battery pack if the ship's special characteristic of operating on the water is considered.

When the battery capacity required for the electric propulsion ship is determined, the battery module satisfying this capacity should be composed. In general, the smallest unit of a battery is a cell, and the battery module is generated by binding many cells together. Often, a

Table 1 List of electric propulsion motors (10 or 20 HP models only)

\begin{tabular}{ccccccc}
\hline Index & Max. rpm & $\mathrm{L}(\mathrm{mm})$ & $\mathrm{B}(\mathrm{mm})$ & $\mathrm{D}(\mathrm{mm})$ & $\begin{array}{c}\text { Weight } \\
(\mathrm{kg})\end{array}$ & $\begin{array}{c}\text { Max. } \\
\text { output } \\
(\mathrm{kw})\end{array}$ \\
\hline 1 & 880 & 671.40 & 350.01 & 357.30 & 177.81 & 7.45 \\
\hline 2 & 1170 & 633.60 & 308.00 & 315.75 & 137.89 & 7.45 \\
\hline 3 & 1765 & 495.73 & 248.01 & 275.36 & 77.11 & 7.45 \\
\hline 4 & 3530 & 495.73 & 248.01 & 275.36 & 77.56 & 7.45 \\
\hline 5 & 880 & 752.35 & 384.99 & 405.21 & 236.78 & 14.90 \\
\hline 6 & 1180 & 709.40 & 350.01 & 357.30 & 205.02 & 14.90 \\
\hline 7 & 1765 & 633.60 & 308.00 & 315.75 & 140.16 & 14.90 \\
\hline 8 & 3530 & 633.60 & 308.00 & 315.75 & 138.80 & 14.90 \\
\hline
\end{tabular}


battery package is composed of many modules. To maximize the performance of the battery, the specifications of each unit component should be the same. It is possible to derive combinations of various battery modules that satisfy the total battery capacity by implementing a database of commercially available products in similar motors. The battery database was based on the lithium-ion batteries of Winston Co., which were used in previous research. ${ }^{25}$

\section{Optimal Arrangement of EPS Components}

\subsection{Problem Definition and Optimization Algorithm}

In the OPE process for the electric propulsion ship, the specifications of the components in the EPS were determined. However, with only the determined specifications, it is impossible to precisely verify whether the requirements were satisfied. It is possible to precisely verify the operating performance after determining both the specifications of the ship's internal components and the arrangements of each component, because the resistance that most affects the ship's operating performance is determined by the weight condition or balance of the ship during operation. For this reason, the operating performance of a ship can be evaluated differently by the arrangements of components, even after the specifications of the components are determined. This study proposes an optimization algorithm for the locations of the EPS components to satisfy specific conditions.

To calculate the equilibrium position, the size of the acting force and its point of action should be clearly understood. However, the EPS components are not a single item and multiple parts are arranged for the battery; it is difficult to calculate the center of gravity for all of the components. Therefore, this study proposes an algorithm to generate arrangements when the EPS components are placed, matching the center of gravity with the specific position defined by the designer.

In this study, the optimal arrangement problem of EPS components was defined as a bitmap-based arrangement problem; thus, the space in which EPS components are arranged is defined in grid form. To define the optimal arrangement problem, the method of expressing the arrangement sequence and geometrical shape of the arrangement target were required. In this study, the arrangement sequence of EPS

components was expressed by using vectors whose components were real numbers. Moreover, the vector components were determined according to the number of arrangement targets, and each component was designed to save real numbers between 0 and 1 . The arrangement sequence of EPS components was defined according to the ranking of each component; the details are shown in Fig. 4(a). The algorithm generating the geometric arrangement starts by assigning sequence numbers to an arrangement space by using the SFC. The SFC is defined so that a line passes all grids without exception, so each sequence number is assigned to adjacent grids in order. Thereafter, the EPS components are allocated to the arrangement spaces fitting the serial numbers, according to the predefined arrangement sequence. For example, if two components with areas of 10 and 5 are allocated in sequence, then grids with sequence numbers from 0 to 9 are assigned to a component with an area of 10 , and grids with sequence numbers from 10 to 14 are assigned to a component with an area of 5. The twodimensional space arrangement algorithms using the SFC are processed as described above; the detailed contents are shown in Fig. 4(b).

Because the two-dimensional arrangement problem was simplified to a one-dimensional problem by using the SFC, the geometric shape and location of components can be derived when the arrangement sequence is determined. To apply this to an optimization algorithm, an

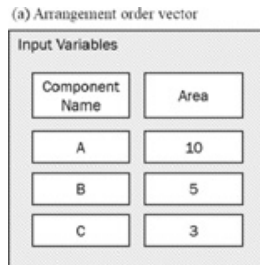

(b) Geonetric arrangement results Input Variables

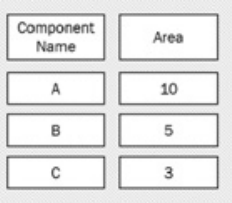

Fig. 4 Algorithm of optimal arrangement process using ordering function and SFC

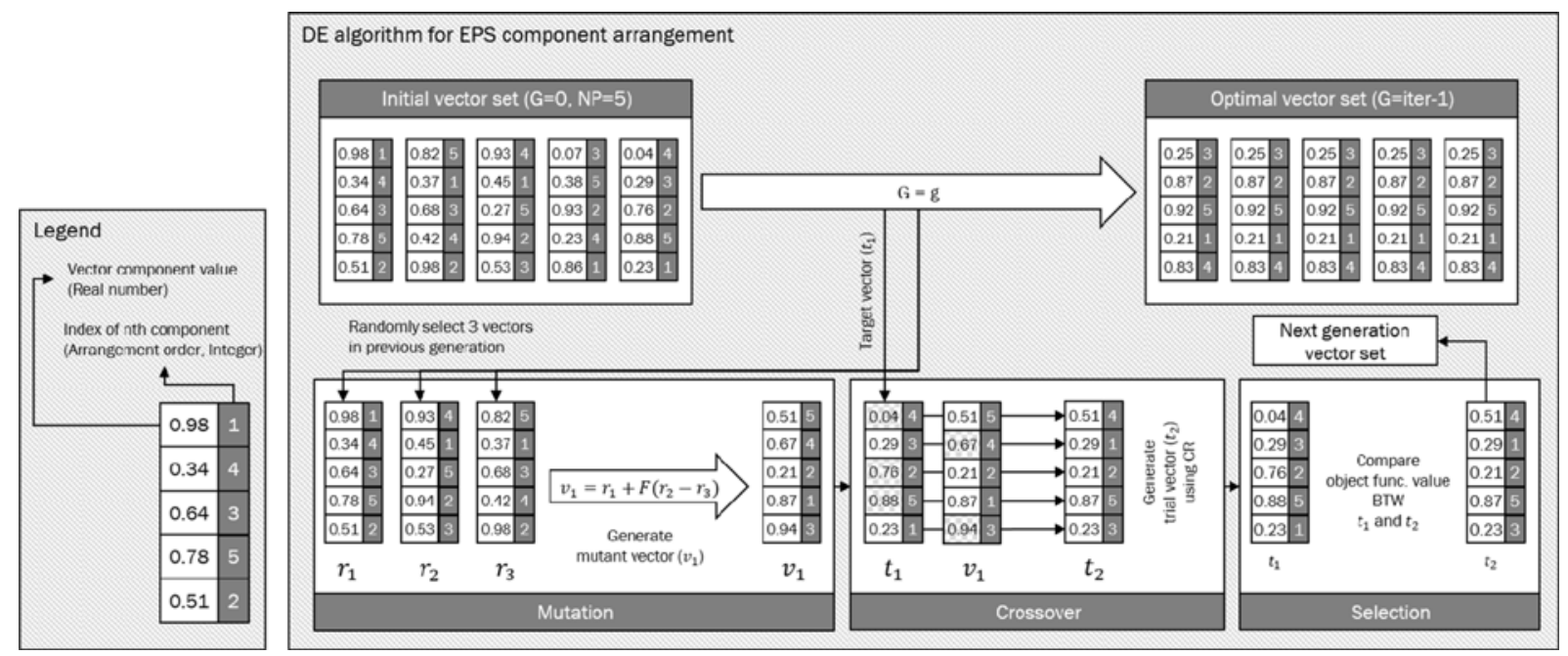

Fig. $5 \mathrm{DE}$ algorithm for EPS component arrangement (sample data) 
object function is defined according to a suitable arrangement standard and an algorithm is required that finds an arrangement to minimize the function. After all, a total of $m+n$ arrangement subjects composed of $m$ components and $n$ grids generate a total of $(m+n)$ ! arrangements. It is almost impossible to directly find the optimal solution because the complexity of the problem increases greatly in this case. Therefore, this study solved the EPS component arrangement problem by using the DE algorithm.

The DE algorithm is composed of four stages: initialization, mutation, crossover, and selection. In the initialization stage, as many vectors as in the number of population (NP) are generated. This study generated as many components of vectors as arrangement subjects, which made it possible to express the arrangement sequence by using each rank. Afterward, the mutation, crossover, and selection stages in Fig. 5 are executed to derive the solution set of next generation. The weight, $\mathrm{F}$, for generating the mutant vector and crossover ratio determining the crossover status of vector components uses values entered by the user. The detailed procedures are shown in Fig. 5.

\subsection{Definition of Input Variables}

To conduct the EPS component arrangement problem, it is necessary to determine the space in which the components will be placed and input the geometrical data for the components. The space in which EPS components are arranged, such as an engine room, is generally rectangular, so it is expressed as a rectangle divided by unit grids. If number of unit grids in the arrangement space is increased, the arrangement result of EPS components is more similar to geometric space of the actual EPS components. However, EPS components have a regular shape; if the arrangement space remains as shown in Fig. 4(b), then the remaining space is defined as a temporary component occupying a grid area. Thus, the smaller the grid size, the larger the number of grids, increasing the complexity of the problem. For this reason, the unit grid size should be determined reasonably.

In addition to the geometric information about EPS components, classification symbols for identifying the type of EPS components and weight information for each component are required. The weight information for each component is used when the overall center of gravity of the arrangement result is calculated. Sample data of the input values used for the optimal arrangement of EPS components are listed in Table 2. Input values are defined as the component type (Battery, Motor, etc.), geometric information represented as unit grid (Length and Breadth) and weight of each EPS components.

\subsection{Object Function}

The objective of the arrangement problem for EPS components is to arrange the components so that the center of gravity corresponds to any position entered by the designer. Therefore, the object function of the

Table 2 Information about EPS components (sample data)

\begin{tabular}{ccccc}
\hline Type & Index & $\begin{array}{c}\text { L } \\
\text { (Unit grid) }\end{array}$ & $\begin{array}{c}\text { B } \\
\text { (Unit grid) }\end{array}$ & $\begin{array}{c}\text { Weight } \\
(\mathrm{kg})\end{array}$ \\
\hline Battery & 1 & 4 & 2 & 20.0 \\
\hline Battery & 2 & 4 & 5 & 40.0 \\
\hline Motor & 3 & 3 & 1 & 10.0 \\
\hline Motor & 4 & 3 & 1 & 10.0 \\
\hline
\end{tabular}

optimization algorithm should include the distance between the center of gravity of the components and the center of gravity input by the designer. The geometric position of the components can be found by seeking the grid corresponding to a serial number, because each grid has a serial number allocated by the SFC. The center of gravity of the arrangement result can be derived through a simple calculation because the weight of each component is entered. One requirement is that the straight-line distance between the computed center of gravity and the entered center of gravity is included in the object function. This is expressed as formula (2). In formula (2), $\left(x_{\text {input }}, y_{\text {input }}\right)$ is a coordinate of the center of gravity entered by the designer and $\left(x_{\text {calc }}, y_{\text {calc }}\right)$ is a coordinate of the calculated center of gravity.

$$
f_{1}=\sqrt{\left(x_{\text {input }}-x_{\text {calc }}\right)^{2}+\left(y_{\text {input }}-y_{\text {calc }}\right)^{2}}
$$

The disadvantage of the arrangement result using the SFC is that an irregular shape, different from the actual shape of the component, may be derived because its shape is determined by the SFC. Therefore, a term related to the aspect ratio is added to the object function to improve it. The difference between the actual aspect ratio and the ratio entered at the initial stage is added to the object function by calculating the ratio of width to length of occupying grids when a geometric arrangement result is produced. If the shape of a component is derived that has the same ratio as initially entered, then the object function value becomes the minimum, 0. Formula (3) expresses this. Here, $a_{i}$ means the ith component of the entered aspect ratio and $b_{i}$ means the calculated aspect ratio of the ith component in an arrangement.

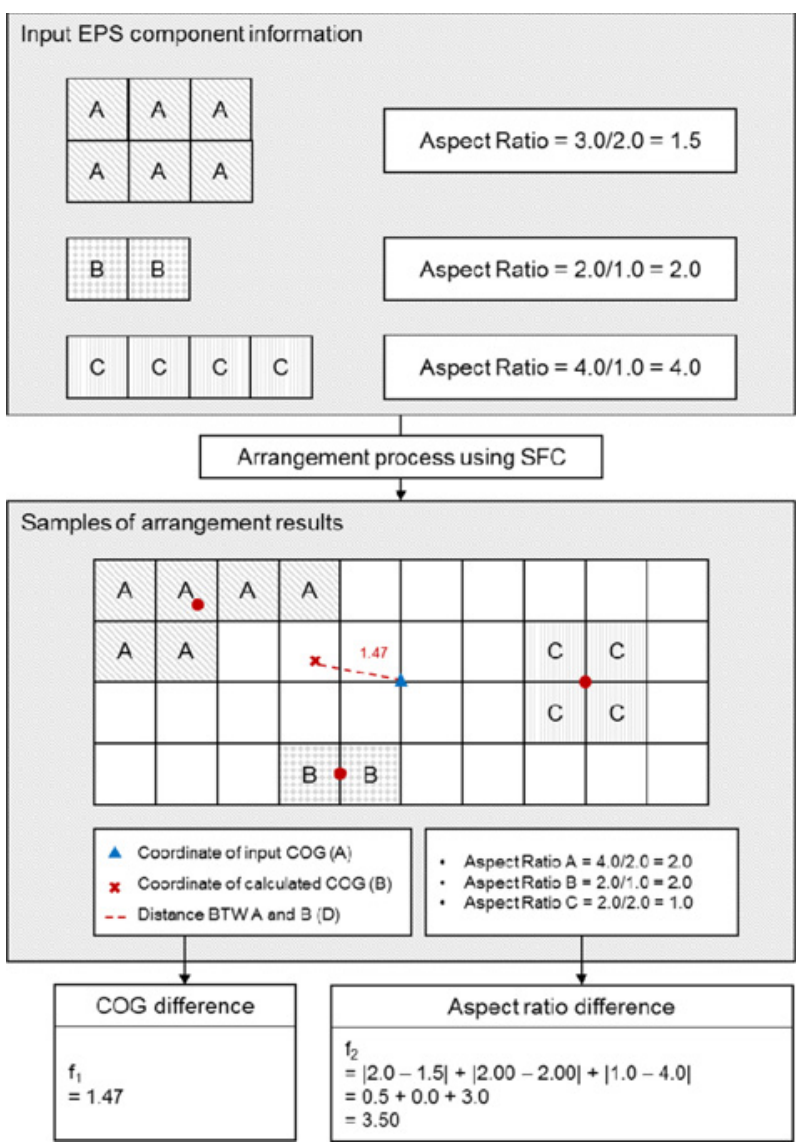

Fig. 6 Calculation sample of object function 


$$
f_{2}=\sum\left|a_{i}-b_{i}\right|
$$

Finally, in the object function, these two terms are added by using weights to consider both differences in center of gravity and aspect ratio. This is summarized as an object function of a multi-objective optimization problem, expressed as formula (4). The detailed calculations for object function are shown in Fig. 6 .

$$
\begin{gathered}
Z=w_{1} f_{1}+w_{2} f_{2} \\
=w_{1} \sqrt{\left(x_{\text {input }}-x_{\text {calc }}\right)^{2}+\left(y_{\text {input }}-y_{\text {calc }}\right)^{2}} \\
+w_{2} \sum\left|a_{i}-b_{i}\right|
\end{gathered}
$$

\section{Implementation and Example}

\subsection{Specifications of Target Ship}

In Chapter 5, the usefulness of the proposed OPE process for an electric propulsion ship and the optimal arrangement algorithm for EPS components is verified by applying them to a real craft. To apply the algorithm, a ship whose diesel propulsion system is to be converted into an EPS was selected as the target ship. The target ship can be classified as a small or medium class leisure ship, with a total length of $16.40 \mathrm{~m}$ and gross tonnage of 18.53 tons. It was designed for a top speed of 12.5 knots; principal dimensions are listed in Table 3. After the specifications of EPS components to be equipped and the optimal places for their arrangement are determined, they were reproduced as a DMU(Digital mockup) model for verification. The results are shown in Fig. 7.

\subsection{Implementation of OPE Process}

The EPS design process for converting a conventional propulsion system to an EPS is divided into two processes, as previously described in Chapters 3 and 4: the process to determine EPS specifications and the process to arrange components based on the specifications. During the OPE process, the maximum operating speed, maximum operating time, initial battery capacity, amount of onboard energy consumption, and upper limit SoC of the battery are defined as input variables for

Table 3 Principal dimensions of target ship

\begin{tabular}{cccc}
\hline Items & Value & Items & Value \\
\hline Length overall & $16.40 \mathrm{~m}$ & Deadweight & 18.53 ton \\
\hline Breadth & $4.50 \mathrm{~m}$ & Fuel oil tank & 1.70 ton \\
\hline Depth & $1.90 \mathrm{~m}$ & Fresh water tank & 1.80 ton \\
\hline Light weight & \multirow{2}{*}{$13.70 \mathrm{ton}$} & Main engine & $\begin{array}{c}265 \mathrm{HP} @ \\
2300 \mathrm{RPM}\end{array}$ \\
\hline
\end{tabular}

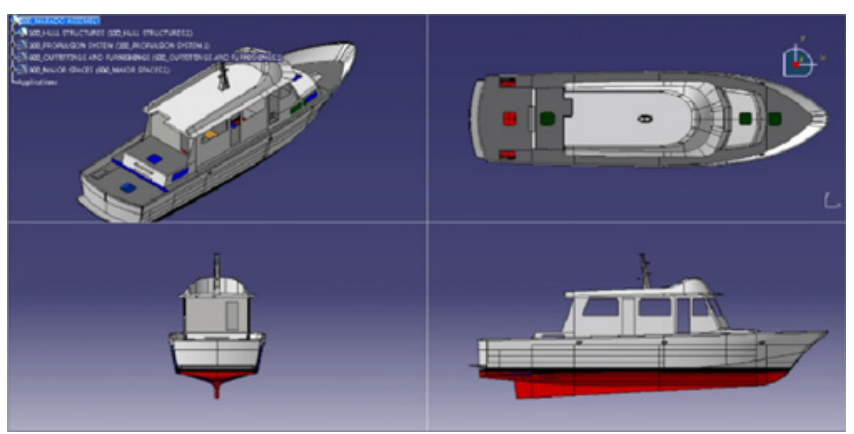

Fig. 7 Digital prototype model of target ship determining the specifications of the EPS. Additionally, the same value as the existing maximum speed was input to satisfy the existing maximum speed. Other variables are assumed as listed in Table 4.

The target ship was originally designed with a top speed of 12.5 knots; the same speed was assumed here to produce the same performance. The maximum operating time and battery capacity were assumed to be 5 hours and $200 \mathrm{kWh}$, respectively. The amount of onboard energy assumption, besides the energy amount used for propulsion, was assumed to be $2.5 \mathrm{~kW}$, considering the required energy for using the management system, navigation system, lighting equipment, and other onboard equipment. Finally, the power curve showing the DHP value for speed, required for determining the maximum output of the motor, was estimated by using the DMU model of the target ship and simulation software. The Holtrop method embedded in the simulation software was used for the resistance according to speed.

The motor output satisfying the maximum speed is calculated through the speed-power curve using the simulation software. As shown in Fig. 8, an output over $100 \mathrm{~kW}$ is required to satisfy the target ship's maximum speed, 12.5 knots. Therefore, a motor that can produce an output over $100 \mathrm{~kW}$ was selected to be mounted on the target ship. Finally, two motors of $75 \mathrm{HP}$ class were selected by using the previously implemented motor information from WEG Co.; these reach maximum speed at a gross output of $103.5 \mathrm{~kW}$.

Next, the capacity of the battery to be mounted on the target ship was calculated. First, the operating time according to speed was derived by using the formula defined in Chapter 3. The limits of operating speed used for variables were set to range from 0.5 knots to 13.0 knots, including the top speed of 12.5 knots. The calculation results are listed in Table 5 and expressed as a graph in Fig. 9, to confirm the trends of changes in operating time and distance according to the speed. Based on

Table 4 Input variables for OPE process

\begin{tabular}{cccc}
\hline Input variables & Symbol & Value & Unit \\
\hline Max. operating time & $t_{\max }$ & 5.0 & $\mathrm{~h}$ \\
\hline Max. speed & $V_{\max }$ & 12.5 & $\mathrm{knots}$ \\
\hline Initial battery capacity & $E_{1}$ & 200.0 & $\mathrm{kWh}$ \\
\hline $\begin{array}{c}\text { Shipboard energy } \\
\text { consumption }\end{array}$ & $E_{2}$ & 2.5 & $\mathrm{~kW}$ \\
\hline $\begin{array}{c}\text { Limit battery } \\
\text { state-of-charge }\end{array}$ & $S O C$ & 85.0 & $\%$ \\
\hline Power curve (DHP) & $D H P(V)$ & $\begin{array}{c}\text { Holtrop method } \\
\text { (by Maxsurf) }\end{array}$ & $\mathrm{kW}$ \\
\hline
\end{tabular}

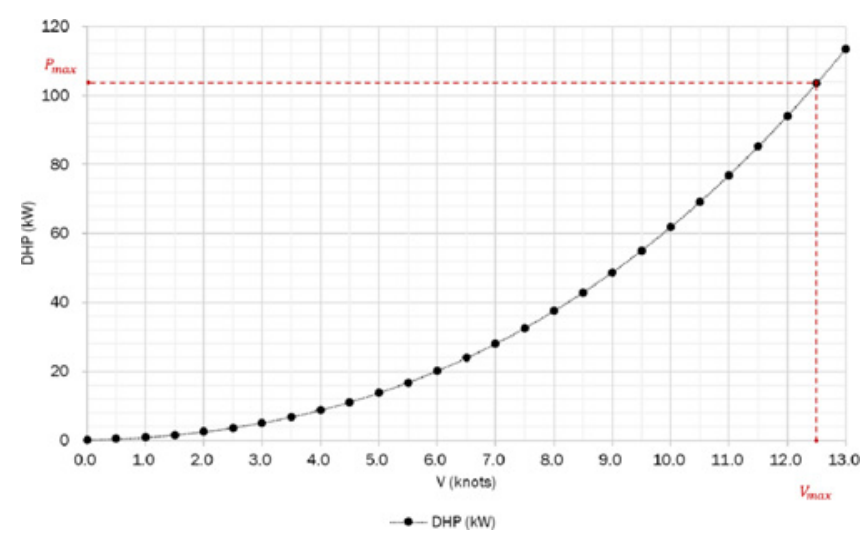

Fig. 8 Speed-DHP curve 
the derived result shown in Fig. 9, it can be confirmed that the operating time constantly decreases as the speed increases. However, the operating distance shows a tendency to increase up to a specific speed, then decrease beyond this speed. This occurs because the amount of energy consumption increases rapidly according to the increase in speed.

According to the OPE defined in Chapter 3, based on the following calculation result, the speed range satisfying the maximum operating time should be derived. In this example, the maximum operating time was assumed to be $5 \mathrm{~h}$. It is confirmed in Table 5 and Fig. 9 that a speed range exceeding $5 \mathrm{~h}$ of operation time is no more than 7.0 knots. Therefore, the rated operating speed of the target ship was determined at 7.0 knots, which is the fastest among all speeds satisfying the maximum operating time. In addition, because the speed satisfying the maximum operating time was derived, the final battery capacity was determined to be $200 \mathrm{kWh}$, as initially entered. The EPS components derived by

Table 5 Calculation results table of operating time and distance

\begin{tabular}{|c|c|c|c|}
\hline Speed (knots) & DHP $(\mathrm{kW})$ & Oper. Time (hour) & Oper. Distance $(\mathrm{km})$ \\
\hline 0.5 & 0.431 & 58.007 & 53.710 \\
\hline 1.0 & 0.879 & 50.314 & 93.173 \\
\hline 1.5 & 1.551 & 41.966 & 116.571 \\
\hline 2.0 & 2.462 & 34.260 & 126.887 \\
\hline 2.5 & 3.627 & 27.744 & 128.444 \\
\hline 3.0 & 5.062 & 22.481 & 124.893 \\
\hline 3.5 & 6.781 & 18.317 & 118.722 \\
\hline 4.0 & 8.799 & 15.045 & 111.447 \\
\hline 4.5 & 11.132 & 12.471 & 103.923 \\
\hline 5.0 & 13.794 & 10.433 & 96.604 \\
\hline 5.5 & 16.801 & 8.808 & 89.710 \\
\hline 6.0 & 20.167 & 7.500 & 83.330 \\
\hline 6.5 & 23.909 & 6.437 & 77.486 \\
\hline 7.0 & 28.040 & 5.567 & 72.158 \\
\hline 7.5 & 32.576 & 4.847 & 67.315 \\
\hline 8.0 & 37.532 & 4.247 & 62.913 \\
\hline 8.5 & 42.922 & 3.743 & 58.912 \\
\hline 9.0 & 48.764 & 3.316 & 55.270 \\
\hline 9.5 & 55.070 & 2.953 & 51.949 \\
\hline 10.0 & 61.857 & 2.642 & 48.917 \\
\hline 10.5 & 69.138 & 2.373 & 46.142 \\
\hline 11.0 & 76.931 & 2.140 & 43.597 \\
\hline 11.5 & 85.249 & 1.937 & 41.258 \\
\hline 12.0 & 94.107 & 1.760 & 39.104 \\
\hline 12.5 & 103.521 & 1.603 & 37.117 \\
\hline 13.0 & 113.506 & 1.465 & 35.279 \\
\hline
\end{tabular}

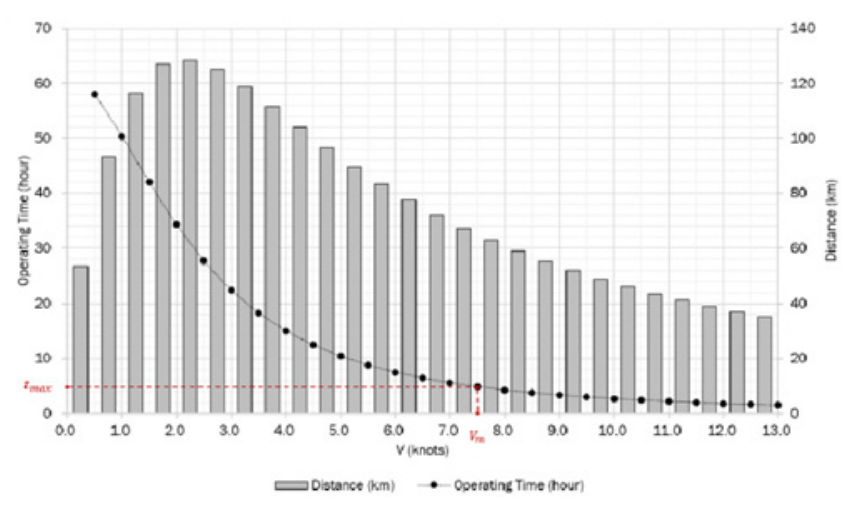

Fig. 9 Calculation results of operating time and distance applying the OPE process are as follows: two motors of $75 \mathrm{HP}$ class, operating speed of 7.0 knots, and battery capacity of $200 \mathrm{kWh}$.

The information for the commercial lithium-ion battery from Winston Co. was used to compose a battery module satisfying the battery capacity, which was derived last. Winston Co. sells battery modules in various capacities; in this study, a basic battery module was determined by considering weight, volume, and voltage after combining the basic components of the battery satisfying $200 \mathrm{kWh}$. Finally, the basic battery module was determined as a WB-LYP300AHA model and the battery package with a total capacity of $203.0 \mathrm{kWh}$ was composed by serially connecting 20 basic modules. Battery packages vary in sizes and numbers according to the number of battery modules included in a unit package. For example, a total of two battery packages are composed when 100 battery modules are combined into a battery package. In this example, the optimal arrangement algorithm for electric propulsion components derived in Chapter 4 was applied to the composition plans for the battery package by producing different plans.

\subsection{Implementation of Optimal Arrangement Algorithm}

Because the target ship in this case is converting its conventional propulsion system to an EPS, the equilibrium position can be maintained by arranging the EPS components to maintain the center of gravity of existing diesel propulsion system components. Therefore, the center of gravity of the existing propulsion system mounted on the target ship and the arrangement space where the EPS components are placed were analyzed by using the DMU model before arranging the EPS components.

The EPS components are arranged in the engine room space before the existing diesel engine is mounted, according to the result of analyzing the arrangement space for the EPS components using the DMU model of the target ship. The size of the arrangement area is as follows: width, $4508 \mathrm{~mm}$; length, $4215 \mathrm{~mm}$; depth, $1880 \mathrm{~mm}$. The length and width were equally set at $4000 \mathrm{~mm}$ for intuitively generating two-dimensional grids. The length of a unit grid was set at $10 \mathrm{~mm}$, as shown in Fig. 10, and a total of 1600 two-dimensional grids were generated: 40 horizontal and 40 vertical grids.

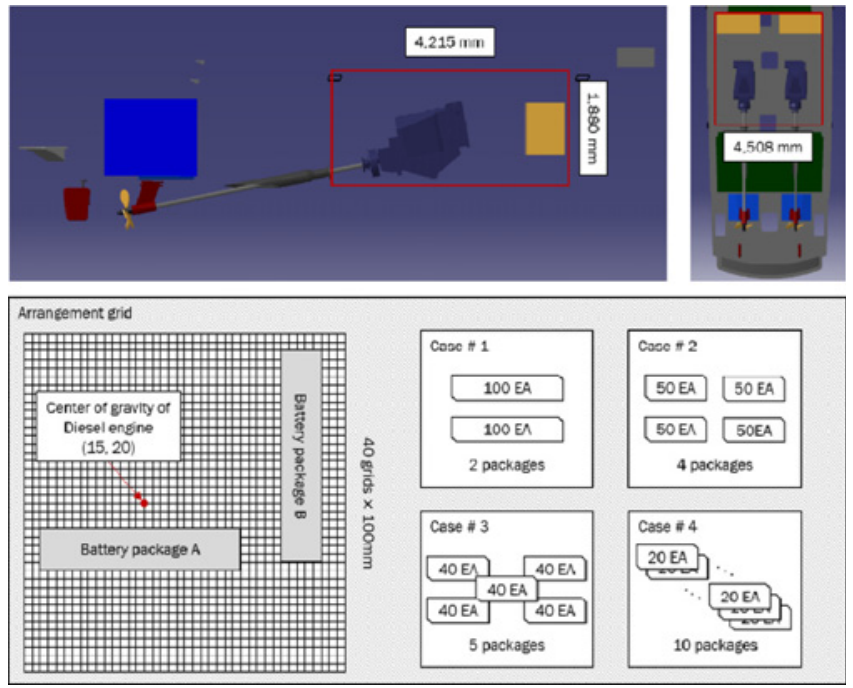

Fig. 10 Target space analysis and battery package arrangement samples 
As mentioned above, four alternative battery packages, which is a target for the arrangement, were set to be generated by changing the number of modules. In the first case, a total of two packages were arranged by composing a package with 100 modules. The arrangement targets were defined by composing a package with 50 modules in the second case, 40 in the third case, and finally, 20 in the fourth case. The size of a unit module is the same as the previously determined WB-LYP300AHA model; it occupies four horizontal grids and one vertical grid. In addition, the weight of a unit module is $9.6 \mathrm{~kg}$. The required input variables for the arrangement
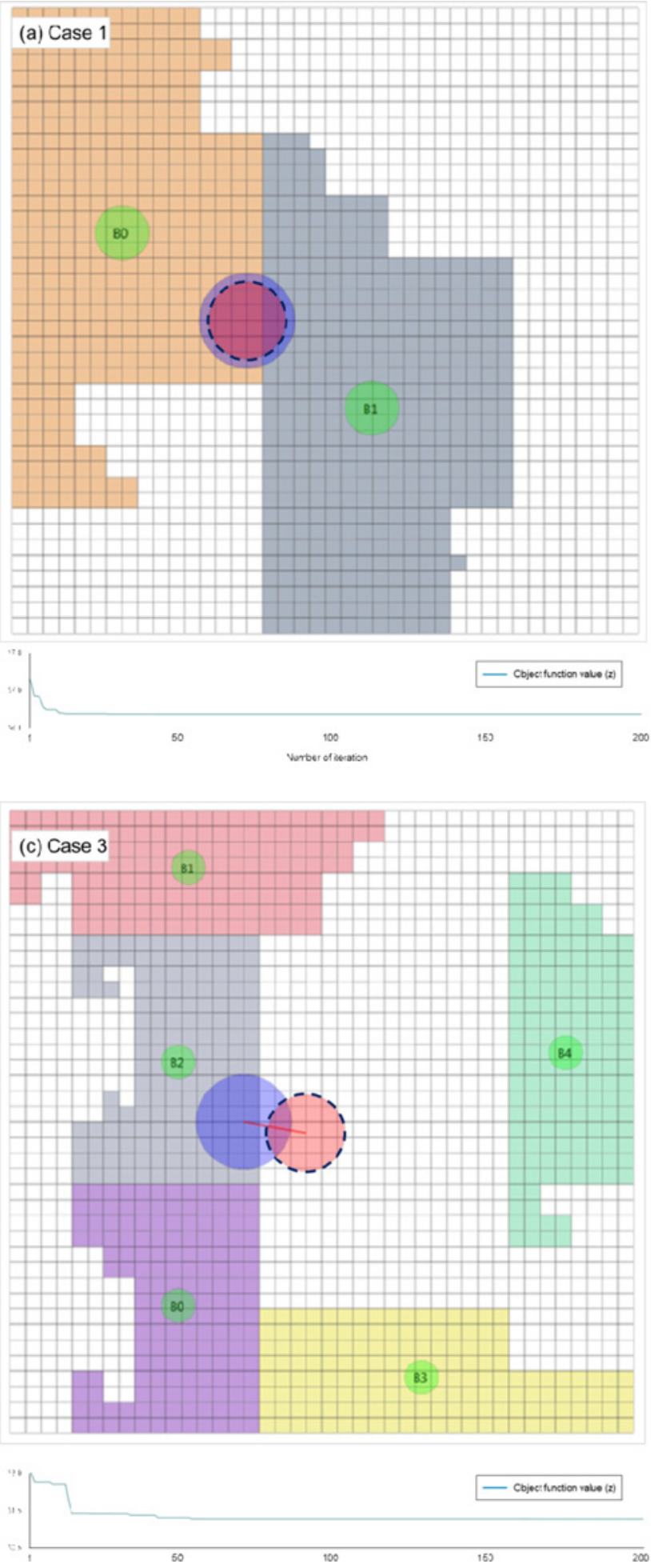

Fig. 11 Optimized battery package arrangement results using application of the EPS components are defined in Table 6.

Table 6 Input variables for EPS component arrangement problem

\begin{tabular}{|c|c|c|c|c|c|}
\hline Case & Type & $\begin{array}{c}\text { L } \\
\text { (Unit } \\
\text { grid) }\end{array}$ & $\begin{array}{c}\text { B } \\
\text { (Unit grid) }\end{array}$ & $\begin{array}{c}\text { Total } \\
\text { weight } \\
(\mathrm{kg})\end{array}$ & $\begin{array}{c}\text { Number of } \\
\text { packages }\end{array}$ \\
\hline 1 & \multirow{4}{*}{$\begin{array}{l}\text { Battery } \\
\text { package }\end{array}$} & 100 & 4 & 960.0 & 2 \\
\hline 2 & & 50 & 4 & 480.0 & 4 \\
\hline 3 & & 40 & 4 & 384.0 & 5 \\
\hline 4 & & 20 & 4 & 192.0 & 10 \\
\hline
\end{tabular}
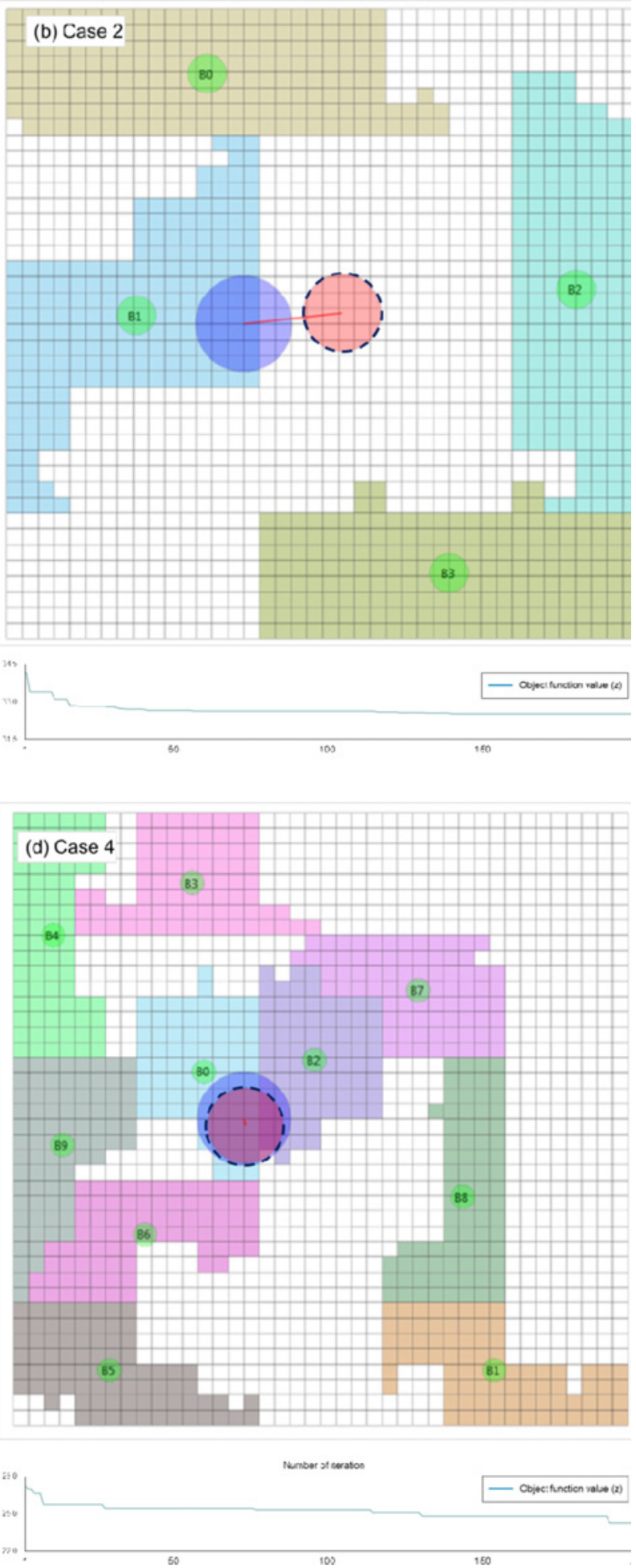


\subsection{Results and Analysis}

The arrangements that minimize the object function value were derived by using the predefined input file. The control variables of the DE algorithm were set at the maximum number of iterations, 200; number of populations, 20; crossover rate, 0.5 ; and mutation weight, 0.6 ; by considering the characteristics of the input file. Four types of battery packages were composed according to the combination of unit modules; the detailed result of each case is summarized in Table 7. The voltage of a battery package is low when a smaller number of modules is used, so this is a comparatively safe combination. However, the final EPS voltage should be selected later, after considering interactions with other components, because it must satisfy the required voltage.

EPS arrangements for each case, derived by using the previously defined algorithm, are shown in Fig. 11. In the arrangement results, the circle with text represents the center of gravity of each battery package and the circle with dotted line represents the center of gravity of the whole battery package. In addition, the other circle represents the center of gravity entered by the designer. The center of each circle corresponds to the coordination of the center of gravity, and the size of each circle was generated to be proportional to the weight of each component.

Each arrangement minimizes the previously defined object function and considers both of center of gravity and shape. However, the shape condition, because it is determined by the SFC as well as the object function value, is different from the actual shape. Therefore, the extracted

Table 7 EPS component arrangement optimization result of target ship (Object function weight: COG weight $\left(w_{1}\right)=0.2$, Aspect ratio weight $\left.\left(w_{2}\right)=0.8\right)$

\begin{tabular}{cccccc}
\hline Case & $\begin{array}{c}\text { \# of battery } \\
\text { packages }\end{array}$ & $\begin{array}{c}\text { Object function value } \\
\text { difference } \\
\left(f_{1}\right)\end{array}$ & $\begin{array}{c}\text { Aspect ratio } \\
\text { difference } \\
\left(f_{2}\right)\end{array}$ & $\begin{array}{c}\text { Total object } \\
\text { function } \\
\text { value } \\
(z)\end{array}$ & $\begin{array}{c}\text { Voltage of } \\
\text { each } \\
\text { package }\end{array}$ \\
\hline 1 & 2 & 0.016 & 46.000 & 36.803 & $340 \mathrm{~V}$ \\
\hline 2 & 4 & 6.275 & 39.100 & 32.535 & $170 \mathrm{~V}$ \\
\hline 3 & 5 & 4.081 & 38.333 & 31.483 & $136 \mathrm{~V}$ \\
\hline 4 & 10 & 0.448 & 30.333 & 24.356 & $68 \mathrm{~V}$ \\
\hline
\end{tabular}

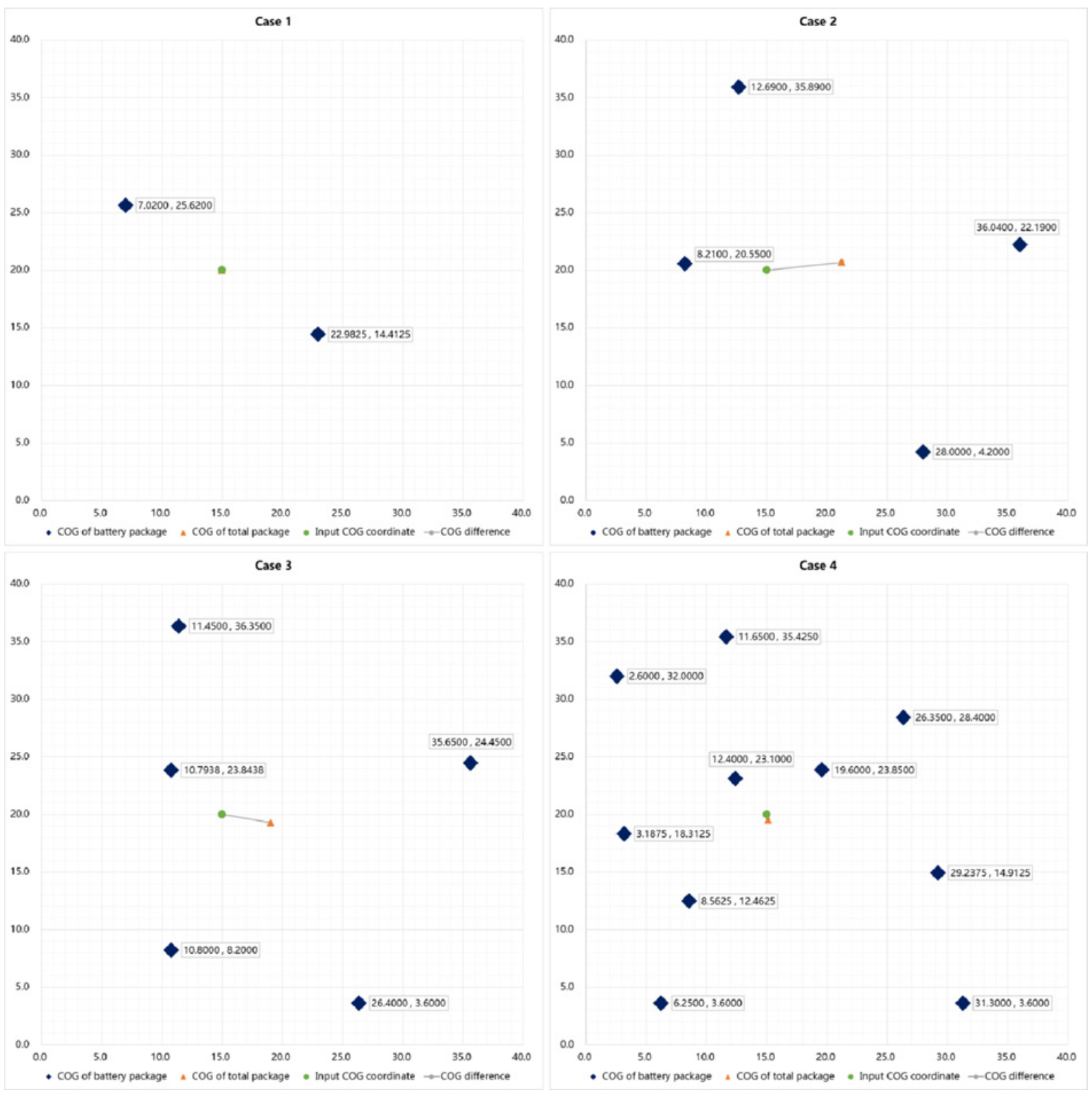

Fig. 12 Optimized battery package arrangement results 
center of gravity of the components derived by this application should be considered when the EPS components are actually arranged.

Fig. 12 shows the result representing the center of gravity of EPS components for each case in a two-dimensional coordination space. In this result, if the distance between the centers of gravity of the existing propulsion system and newly arranged propulsion system is minimized, then it is favorable to estimate the resistance and stability in the design process because the equilibrium position does not change.

Finally, for determining the location of the battery package, the design plan for EPS components should be generated by using the center of gravity of the components and geometrical shape of the actual battery package. Because this example is a case in which a conventional propulsion ship is converted to an electric propulsion ship, it is important to determine the location of the EPS components so that their center of gravity is the same as the existing center of gravity for the propulsion system components. However, the EPS components should be arranged by considering not only the center of gravity but also the safety of EPS components, such as voltage, output current, complexity of electric wiring system, and maintenance clearance.

Therefore, the case 1 in Fig. 11 was determined as the final combination of EPS components. The reasons are as follow: First, the nominal capacity of the previously determined WB-LYP300AHA model is $300 \mathrm{Ah}$. The cases 2, 3, 4 in Fig. 11 are not feasible solutions from an electric safety point of view, because the cases required higher current system than the determined battery system. Second, most common electric vehicles and crafts do not use high voltage and low current battery packs, considering their safety and efficiency. But sometimes electric propulsion naval ships use high current capacity system, ${ }^{26}$ because of their weapon systems. Third, the high current ampacity of electric wiring system greatly affects the weight increase per length of the wiring system. Finally considering stability characteristics of the craft, the case 1 was determined. The center of gravity and specification of each component derived in advance are to be arranged in the target ship's engine room. At this time, the space where the components are placed was ensured to be solely in the engine room, as defined in Fig. 10, and the center of gravity of each component was used as represented in Figs. 11 and 12. In final results, the voltage of each battery package is $340 \mathrm{~V}$ and 2 battery packages are included. And also the total weight and battery capacity are $960.0 \mathrm{~kg}$ and $203.0 \mathrm{kWh}$, as derived in the OPE process. The designer of the EPS components should derive arrangements to be applied to an actual ship based on these initial design results.

\section{Conclusions}

This study proposed a process to determine the specifications of EPS components while designing an electric propulsion ship, in addition to an optimal arrangement algorithm considering the center of gravity of EPS components. The algorithm for the specifications of components in an EPS determines the motor and battery capacity that satisfy the user-defined maximum speed and operating time. The motor specification is derived by analyzing resistance to the design speed of the ship; a motor that can satisfy the maximum speed should be selected. In the stage of determining the battery specification, after calculating a ship's possible operating time according to speed, the battery capacity is determined by verifying the existence of a speed that satisfies the maximum operating time.

The optimal arrangement algorithm uses the SFC, which fills the space without exception; and the DE algorithm, which solves optimization problems. An application was developed for efficient calculation. The application produces the following outputs: the geometrical shape of the derived arrangement, the trend of change for the object function, and the center of gravity of each component. The object function that evaluates the arrangements makes it possible to simultaneously consider the differences in center of gravity and aspect ratio by using weight values. The reason for considering the center of gravity as an evaluation standard is that the center of gravity and weight in a ship are important factors that determine the equilibrium of the ship during operation. Because the result of the arrangement algorithm using the SFC can be generated irregularly, the aspect ratio was added to the object function for optimal arrangement and the actual geometric position was arranged by the designer using the center of gravity.

Finally, the usefulness of the algorithms was verified by applying them to the process of converting a dilapidated conventional propulsion ship to an electric propulsion ship. The target ship is a small to medium leisure craft.

The motor was selected to satisfy the maximum speed requirements of the previous conventional propulsion ship and the battery capacity was calculated at the energy amount to satisfy the maximum operating time by considering the ship's usage. After calculating the total energy amount of the battery, the basic battery module was selected by using a database implemented in advance, and four optimal arrangements of battery packages were derived by changing the compositions of the packages.

The algorithms developed in this study are systematic approaches that can be applied to the initial design stage of electric propulsion ships, so there are limitations for determining the detailed specifications. However, because the design process of an electric propulsion ship is not as advanced as that for other means of transportation, it is expected that this initial design of an electric propulsion ship can be improved based on the contents of this study. The optimal motor output and battery capacity were determined, which may reduce oil costs for users.

\section{ACKNOWLEDGEMENT}

This research was financially supported by the Advanced Naval Vessel Research Laboratory funded by the Ministry of Defense of the Korean Government (Grant No. 0457-20120032) and the Ministry of Science, ICT and Future Planning (MSIP), National Research Foundation of Korea (NRF) and Jeonnam Science \& Technology Promotion Center (JNSP) through the research \& development project of Jeonnam Science Park.

\section{REFERENCES}

1. Park, C. W., Kwon, K. S., Kim, W. B., Min, B. K., Park, S. J., et al., "Energy Consumption Reduction Technology in Manufacturing - A Selective Review of Policies, Standards, and Research," Int. J. Precis. Eng. Manuf., Vol. 10, No. 5, pp. 151-173, 2009. 
2. Hideki, Y., Hiroaki, M., and Aiichiro, S., "Energy Saving Technology of the Diesel-electric Propulsion System for Japanese Coastal Vessels," IHI Engineering Review, Vol. 44, No. 1, pp. 12-16, 2011.

3. Sadr, S. and Khanzade, M. H., "Ship Electrical Propulsion System," Journal of Basic and Applied Scientific Research, Vol. 3, No. 6, pp. 655-660, 2013.

4. Younes, Z., Boudet, L., Suard, F., Gerard, M., and Rioux, R., "Analysis of the Main Factors Influencing the Energy Consumption of Electric Vehicles,” IEEE, pp. 247-253, 2013.

5. Ehsani, M., Rahman, K. M., and Toliyat, H. A., "Propulsion System Design of Electric and Hybrid Vehicles," IEEE Transactions on Industrial Electronics, Vol. 44, No. 1, pp. 19-27, 1997.

6. Kempton, W., Tomic, J., Letendre, S., Brooks, A., and Lipman, T., "Vehicle-to-grid Power: Battery, Hybrid and Fuel Cell Vehicles as Resources for Distributed Electric Power in California," Institute of Transportation Studies Report, pp. 1-94, http://escholarship.org/uc/ item/0qp6s4mb\#page-1 (Accessed 23 May 2014)

7. Yoon, J. I., Truong, D. Q., and Ahn, K. K., “A Generation Step for an Electric Excavator with a Control Strategy and Verifications of Energy Consumption,” Int. J. Precis. Eng. Manuf., Vol. 14, No. 5, pp. 755-766, 2013.

8. Kim, Y. J., Song, B., and Kim, J., "Load Torque Estimation for a Parallel Hybrid Agricultural Tractor in Field Operations," Int. J. Precis. Eng. Manuf., Vol. 14, No. 10, pp. 1865-1868, 2013.

9. Prousalidis, J. M., Hatziargyriou, N. D., and Papadias, B. C., "On Studying Ship Electric Propulsion Motor Driving Schemes," Proc. of the $4^{\text {th }}$ International Conference on Power System Transients, Paper No. 01IPST016, 2001.

10. McCoy, T. J., "Trends in Ship Electric Propulsion" Proc. of the IEEE Summer Meeting on Power Engineering Society, Vol. 1, pp. 343-346, 2002.

11. Freire, T., Sousa, D. M., and Branco, P. J. C., "Aspects of Modeling an Electric Boat Propulsion System," Proc. of the IEEE International Conference on Computational Technologies in Electrical and Electronics Region 8, Paper No. 11488767, pp. 812-817, 2010.

12. Tianhao, T., Han, J., Yao, G., and Feng, Y., "Development of a PEM Fuel Cell Boat," Proc. of the IEEE $12^{\text {th }}$ International Conference on Power Electronics and Motion Control, Paper No. 432, pp. 13851388, 2006.

13. Nóbrega, J., Dan, T. C., and Rubanenco, I, "Electric Propulsion Applied for Research Vessel," Proc. of the International Conference on Renewable Energies and Power Quality, Paper No. 240, 2013.

14. Bevan, A. I., Züttel, A., Book, D., and Harris, I. R., "Performance of a Metal Hydride Store on the 'Ross Barlow' Hydrogen Powered Canal Boat,” Faraday Discussions, Vol. 151, pp. 353-367, 2011.

15. Lee, C. S., Heo, E. Y., and Kim, D. S., "An Efficient Nesting Algorithm Recognizing the Placing Area," Int. J. Precis. Eng. Manuf., Vol. 13, No. 10, pp. 1917-1920, 2012.
16. Bozer, Y. A., Meller, R. D., and Erlebacher, S. J., "An Improvementtype Layout Algorithm for Single and Multiple-floor Facilities," Management Science, Vol. 40, No. 7, pp. 918-932, 1994.

17. Storn, R. and Price. K, "Differential Evolution - A Simple and Efficient Heuristic for Global Optimization over Continuous Spaces," Journal of Global Optimization, Vol. 11, No. 4, pp. 341359, 1997.

18. Ardia, D., Boudt, K., Carl, P., Mullen, K. M., and Peterson, B. G., "Differential Evolution with DEoptim," R Journal, Vol. 3, No. 1, pp. 27-34, 2011.

19. Lichtblau, D., "Differential Evolution in Discrete and Combinatorial Optimization," Mathematica Tutorial Notes, pp. 1-30, 2010.

20. Vegh, V., Pierens, G. K., and Tieng, Q. M., “A Variant of Differential Evolution for Discrete Optimization Problems Requiring Mutually Distinct Variables," International Journal of Innovative Computing, Information and Control, Vol. 7, No. 2, pp. 897-914, 2011.

21. Jeong, Y. K., Lee, D. K., Jeong, U. C., Ryu, C. H., Oh, D. K., et al., "A Study on the Operating Performance Estimation Process of Electric Propulsion Systems for a 2.5 Displacement ton Class Catamaran Fishing Boat," Journal of Ocean Engineering and Technology, Vol. 27, No. 5, pp. 1-9, 2013.

22. MAN Diesel \& Turbo, "Basic Principles of Ship Propulsion," http:// www.mandieselturbo.com/1005405/Press/Publications/TechnicalPapers/Marine-Power/Low-Speed/Basic-Principles-of-ShipPropulsion.html (Accessed 25 February 2014)

23. Zeraoulia, M., Benbouzid, M. E. H., and Diallo, D., "Electric Motor Drive Selection Issues for HEV Propulsion Systems: A Comparative Study," IEEE Transactions on Vehicular Technology, Vol. 55, No. 6, pp. 1756-1764, 2006.

24. WEG Equipamentos Eletricos SA, "WEG e-Technical Catalog," http:// www.weg.com.br/catalog/index.asp?p_categoria=28\&p_produto=394\& p_table=yes (Accessed 25 February 2014)

25. Winston Battery Limited, "Lithium-ion Power Battery," http:// en.winston-battery.com/index.php/products/power-battery (Accessed 25 February 2014)

26. Pifer, R. J., "Modeling of the Electric Ship," California. Naval Postgraduate School, pp. 1-75, http://hdl.handle.net/10945/5254, (Accessed 23 May 2014) 